\title{
Avaliação de herbicidas de pós-emergência na cultura da cebola.
}

\author{
Jeferson Zagonel; Marie Y. Reghin; Wilson S. Venâncio \\ UEPG, Praça Santos Andrade s/n, 84.010-790, Ponta Grossa - PR. e.mail:
}

\section{RESUMO}

O objetivo deste trabalho foi avaliar a eficiência e a seletividade do herbicida clethodim, em duas formulações (120 e $240 \mathrm{~g} / \mathrm{l})$, no controle de plantas daninhas na cultura da cebola. $\mathrm{O}$ experimento foi instalado na Fazenda Escola da UEPG, em Ponta Grossa (PR), no ano de 1998. O delineamento experimental utilizado foi blocos ao acaso com quatro repetições, constando dos tratamentos: clethodim $(120 \mathrm{~g} / \mathrm{l}+$ óleo mineral) nas doses de 72, 84 e $96 \mathrm{~g}$ i.a./ha; clethodim ( $240 \mathrm{~g} / \mathrm{l}) \mathrm{na}$ dose de $84 \mathrm{~g}$ i.a./ha adicionado de 1,0 1/ha de óleo mineral (Assist); testemunha capinada e testemunha sem capina. A cultivar de cebola utilizada foi Baia Periforme e as plantas daninhas predominantes no experimento foram Brachiaria plantaginea (capim-papuã), Digitaria horizontalis (capim-milhã) e Eleusine indica (capim pé-de-galinha). As avaliações de controle e de fitotoxicidade foram efetuadas aos 7 , 14, 28 e 42 dias após a aplicação dos tratamentos (DAA) onde verificou-se que o clethodim (120 g/l) nas doses de 84 e $96 \mathrm{~g}$ i.a./ha foi igualmente eficiente ao clethodim $(240 \mathrm{~g} / \mathrm{l})$ no controle sobre Brachiaria plantaginea, Digitaria horizontalis e Eleusine indica; esses tratamentos mostraram produção similar e superior à verificada para a testemunha sem capina e causaram leve redução no porte das plantas de cebola aos 7 dias após sua aplicação, o que não foi mais observado nas avaliações posteriores.

\begin{abstract}
Evaluation of herbicides on post emergent weed control in onion crop.

This study had the purpose of evaluating the efficiency and selectivity of the herbicide clethodim, in two formulations (120 and $240 \mathrm{~g} / \mathrm{l}$ ) for weed control in onion crop. The experiment was realized at the University of Ponta Grossa, in Brazil, in 1998. The experimental design was of randomized blocks with four replicates. The following treatments were evaluated: clethodim $(120 \mathrm{~g} / \mathrm{L}+$ mineral oil) using doses of 72, 84 and $96 \mathrm{~g}$ i.a./ha; clethodim (240 $\mathrm{g} / \mathrm{L}$ ) with $84 \mathrm{~g}$ i.a./ha added with $1.0 \mathrm{~L} / \mathrm{ha}$ of mineral oil; weed free and weedy. The onion cultivar used was Baia Periforme and the following weeds were prevailing: Brachiaria plantaginea (capimpapuã), Digitaria horizontalis (capim-milhã) and Eleusine indica (capim-pé-de-galinha). Evaluations were performed at 7, 14, 28 and 42 days after treatments applications when it was observed that clethodim $(120 \mathrm{~g} / \mathrm{L})$ at the doses 84 and $96 \mathrm{~g}$ i.a./ha and clethodim $(240 \mathrm{~g} / \mathrm{L})$ were similar and showed efficient control to Brachiaria plantaginea, Digitaria horizontalis and Eleusine indi$\mathrm{ca}$; these treatments caused a slight reduction of plants height at 7 days after application but later on it was no more observed. The production from these treatments was similar among them; however they were superior when compared to control without weeding.
\end{abstract}

Palavras-chave: Allium cepa L, plantas daninhas, controle

Keywords: Allium cepa L.; weeds; chemical control. químico.

(Aceito para publicação em 11 de setembro de 2.000)

$\mathrm{E}$ ntre os fatores de produção importantes para a cultura da cebola, que ocupa o quarto lugar em importância econômica (Mascarenhas \& Rocha, 1991), destaca-se o controle adequado de plantas daninhas. Experiências de campo, demonstraram que os danos causados por essas plantas são de igual magnitude ou maiores que os ocasionados por insetos e pragas (Mascarenhas, 1986). Na cultura da cebola, as plantas daninhas constituem um sério problema, porque a planta é de porte baixo e seu desenvolvimento inicial é relativamente lento. Além disso, possui folhas eretas, não cobrindo bem a superfície do solo, o que permite a germinação das sementes de plantas daninhas em qualquer fase de desenvolvimento da cultura. Nos sistemas de cultivo utilizados, tanto no direto como no transplantado, o espaçamento entre plantas é pequeno, o que dificulta e encarece a capina ma- nual e praticamente impossibilita a mecanizada. O ciclo longo desta cultura, exige que sejam feitas várias capinas para evitar que as plantas sofram interferência das plantas daninhas. Estes fatores tornam inviável o cultivo da cebola quando não se tem um bom programa de controle de plantas daninhas. Para tal, é de suma importância saber em que época ou período elas apresentam maior interferência sobre a cultura. Esse período, denominado por Pitelli \& Durigan (1984) de período crítico de prevenção da interferência (PCPI), possui uma amplitude que varia de acordo com o clima, com a população de plantas daninhas e com o balanço entre as espécies de folhas estreitas e de folhas largas. Em cebola de semeadura direta, a interferência das plantas daninhas é muito mais prejudicial, reduzindo 30,68 e $94 \%$ da produção, quando a duração da interferência após emergência for de quatro, cinco e seis semanas, respectivamente (Schadbolt \& Holm, 1956). As primeiras quatro semanas de crescimento são críticas para a produção de cebola e o máximo de produção de bulbos é obtido quando a cultura fica livre da presença de plantas daninhas por sete a oito semanas após o transplante (Paller et al., 1971). A interferência das plantas daninhas durante todo o ciclo da cultura reduziu a produção em até $92 \%$, segundo Ferreira (1985). O uso de herbicidas seletivos, tanto na produção de mudas como na cultura proveniente de semeadura direta ou de transplantio de mudas, reduz o esforço humano, melhora a capacidade de trabalho e contribui para melhorar a produção e a qualidade dos bulbos. Entre os herbicidas recomendados para o uso em cebola, destaca-se o clethodim, do grupo químico das ciclohexenonas e de ação pós-emergente, que objetiva o controle de gramíneas 
Tabela 1. Avaliação de herbicidas no controle de plantas daninhas em cebola. Ponta Grossa, UEPG, 1998.

\begin{tabular}{|c|c|c|c|c|c|c|c|c|c|c|c|c|c|c|}
\hline \multirow{2}{*}{ Tratamentos } & \multirow{2}{*}{$\begin{array}{c}\text { Dose } \\
\text { i.a. } \\
\text { (g/ha) }\end{array}$} & \multicolumn{3}{|c|}{07 DAA $^{1}$} & \multicolumn{3}{|c|}{14 DAA $^{1}$} & \multicolumn{3}{|c|}{28 DAA $^{1}$} & \multicolumn{3}{|c|}{42 DAA $^{1}$} & \multirow{2}{*}{$\begin{array}{l}\text { Rendim. } \\
\left(\mathrm{g} / \mathrm{m}^{2}\right)\end{array}$} \\
\hline & & (1) & (2) & (3) & (1) & (2) & (3) & (1) & (2) & (3) & (1) & (2) & (3) & \\
\hline 1. Clethodim $(120 \mathrm{~g} / \mathrm{l})$ & 72 & $66,2 \mathrm{c}$ & $17,5 \mathrm{~b}$ & $17,5 \mathrm{c}$ & $82,5 \mathrm{~b}$ & $23,7 \mathrm{c}$ & $27,5 b$ & $81,2 \mathrm{~b}$ & $27,5 \mathrm{~b}$ & $21,2 \mathrm{~b}$ & $85,0 \mathrm{~b}$ & $38,7 \mathrm{~b}$ & $30,0 \mathrm{~b}$ & 657 \\
\hline 2. Clethodim (120 g/l) & 84 & $67,5 \mathrm{c}$ & $68,7 a$ & $62,5 \mathrm{~b}$ & $92,5 a$ & $80,0 \mathrm{~b}$ & $73,7 a$ & $97,2 a$ & $90,7 a$ & $92,0 a$ & $97,2 a$ & $90,0 a$ & $87,5 \mathrm{a}$ & 762 bc \\
\hline 3. Clethodim (120 g/l) & 96 & $75,0 a b$ & $72,5 a$ & $72,5 a b$ & $98,0 a$ & $86,2 a b$ & $86,2 a$ & $98,0 a$ & $95,2 a$ & $97,2 \mathrm{a}$ & $98,5 a$ & $99,0 a$ & $98,5 a$ & $842 a b c$ \\
\hline 4. Clethodim $\left(240 \mathrm{~g} / \mathrm{l}^{3}\right.$ & 84 & $80,0 a$ & $75,0 a$ & $76,2 a$ & $97,2 a$ & $92,5 a$ & $91,2 \mathrm{a}$ & $98,0 a$ & $97,2 a$ & $98,0 a$ & $99,0 a$ & $97,7 a$ & $99,0 a$ & $932 \mathrm{ab}$ \\
\hline 5. Test. capinada & - & 100 & 100 & 100 & 100 & 100 & 100 & 100 & 100 & 100 & 100 & 100 & 100 & $1015 a$ \\
\hline 6. Test. sem capina & - & 0 & 0 & 0 & 0 & 0 & 0 & 0 & 0 & 0 & 0 & 0 & 0 & 407 \\
\hline C.V. (\%) & - & 5,44 & 9,26 & 10,0 & 3,32 & 4,86 & 12,0 & 1,47 & 5,86 & 4,32 & 3,50 & 6,63 & 11,0 & 12,5 \\
\hline
\end{tabular}

Nas colunas, médias seguidas de mesma letra, não diferem significativamente pelo teste de Tukey ( $\mathrm{p}>5 \%$ ).

*/ Percentual de controle dos herbicidas sobre plantas daninhas, onde $0 \%$ corresponde a "sem controle" e $100 \%$ a "controle total".

1/ Plantas daninhas controladas, onde (1) Brachiaria plantaginea (capim-papuã); (2) Digitaria horizontalis (capim-milhã); (3) Eleusine indica (capim pé-de-galinha), DAA= Dias após a aplicação, C.V. = coeficiente de variação.

2/ i.a./ha = ingrediente ativo aplicado por hectare

3/Recebeu adição de óleo mineral a $0,5 \%$ v/v (1,0 1/ha de Assist)

anuais e perenes, entre as quais Brachiaria plantaginea, Digitaria horizontalis e Eleusine indica (Lorenzi, 1994; Andrei, 1996; Rodrigues, 1998). Para o clethodim (240 g/l), deve ser adicionado óleo mineral para melhorar sua eficiência. Uma nova formulação, contendo óleo mineral, vem sendo avaliada na concentração de $120 \mathrm{~g} / \mathrm{l}$ e objetiva igual controle a de $240 \mathrm{~g} / \mathrm{l}$, sem a necessidade da mistura no tanque com óleo mineral. O presente trabalho teve como objetivo, avaliar a eficiência e a seletividade do herbicida clethodim, em duas formulações, no controle de plantas daninhas na cultura da cebola.

\section{MATERIAL E MÉTODOS}

$\mathrm{O}$ experimento foi instalado na Fazenda Escola da UEPG, no município de Ponta Grossa (PR), em 1998. O delineamento experimental utilizado foi blocos ao acaso, com seis tratamentos: clethodim (120 g/l + óleo mineral) nas doses de 72, 84 e $96 \mathrm{~g}$ i.a./ha; clethodim (240 g/l) na dose de $84 \mathrm{~g}$ i.a./ha adicionado de 1,0 1/ha de óleo mineral; testemunha capinada e testemunha sem capina, com quatro repetições. As parcelas apresentaram área total de $6,0 \mathrm{~m}^{2}(5,0$ $\mathrm{x} 1,2 \mathrm{~m})$ e área útil de $4,0 \mathrm{~m}^{2}(4,0 \times 1,0$ $\mathrm{m})$. O transplante das mudas foi realizado no dia 13/09/98, manualmente, utilizando-se o espaçamento de $30 \mathrm{~cm}$ entre linha e entre plantas. A cultivar de cebola utilizada foi Baia Periforme, adubada com $600 \mathrm{~kg} / \mathrm{ha}$ de adubo de fór- mula 4-14-8 nos sulcos de plantio. A colheita foi realizada no dia 18/12/99, colhendo-se os bulbos da área útil das parcelas. Os tratamentos foram aplicados no dia 28/10/98 através de pulverizador de pressão constante à base de $\mathrm{CO}_{2}$, equipado com bicos de jato leque XR 110.02 espaçados de $0,50 \mathrm{~m}$ um do outro. A pressão de trabalho foi $30 \mathrm{lb} / \mathrm{pol}^{2}$, resultando num volume de calda de 200 1/ha. As avaliações de controle de plantas daninhas foram efetuadas aos 7, 14, 28 e 42 dias após a aplicação dos tratamentos. A metodologia de avaliação utilizada foi a visual, comparando-se o controle exercido pelos herbicidas com a testemunha sem capina, onde " $0 \%$ " correspondeu a "sem controle" e " $100 \%$ " a "controle total". Este procedimento é o mais usual quando o número de plantas daninhas é elevado (Sociedade Brasileira da Ciência das Plantas Daninhas, 1995; Velini, 1995). Considerou-se eficiente o tratamento que apresentou, sobre cada planta daninha, porcentagem de controle igual ou superior a $80 \%$. As plantas daninhas predominantes no experimento foram capim-papuã, capim-milhã e capim péde-galinha, que no dia da aplicação apresentavam em média de um a três perfilhos. Os dados obtidos foram submetidos à análise da variância pelo teste F. As médias foram comparadas pelo teste de Tukey no nível de 5\% de probabilidade. $\mathrm{Na}$ análise das avaliações de controle, foram comparados somente os resultados dos tratamentos herbicidas, isolando-se as testemunhas.

\section{RESULTADOS E DISCUSSÃO}

As condições climáticas ocorridas durante a condução do experimento, foram adequadas ao desenvolvimento da cultura e para a atuação dos produtos, que foram aplicados nas infestantes em pleno desenvolvimento vegetativo. Sobre Brachiaria plantaginea, observouse que aos 7 dias após a aplicação dos tratamentos (DAA), ainda não era possível avaliar o potencial de controle dos produtos, entretanto, as avaliações subsequentes (14, 28 e 42 DAA), mostraram um controle eficiente sobre essa planta daninha (Tabela 1). Nessas avaliações, o clethodim (120 g/l) na dose de $72 \mathrm{~g}$ i.a./ha apresentou controle eficiente, porém, inferior ao verificado para os demais tratamentos. As plantas de Digitaria horizontalis eram as que se encontravam em estádios de desenvolvimento mais avançados na época da aplicação dos tratamentos, apresentando em média de 2 a 3 perfilhos. Sobre as plantas nesse estádio, o clethodim (120 g/l) na dose de $72 \mathrm{~g}$ i.a./ha não apresentou controle eficiente, entretanto, para as doses de 84 e 96 g i.a./ha e na formulação de $240 \mathrm{~g} / \mathrm{l}$, observou-se um controle eficiente nas avaliações aos 14 , 28 e 42 DAA. Sobre Eleusine indica, o clethodim (240 g/l) e o mesmo produto na formulação de $120 \mathrm{~g} / \mathrm{l}$, nas doses de 84 e $96 \mathrm{~g}$ i.a./ha foram eficientes no controle sobre essa invasora aos 14, 28 e 42 DAA, sem diferenças significativas en- 
tre as porcentagens de controle observadas para esses tratamentos. Quanto à fitotoxicidade, o clethodim $(120 \mathrm{~g} / \mathrm{l})$ nas doses de 84 e 96 g i.a./ha e clethodim $(240 \mathrm{~g} / \mathrm{l})$ proporcionaram uma leve redução no porte das plantas de cebola aos 7 DAA, o que não foi observado nas demais avaliações e não afetou o desenvolvimento da cebola. Todos os tratamentos mostraram produção superior à testemunha sem capina e os tratamentos com clethodim $(240 \mathrm{~g} / \mathrm{l})$ e clethodim (120 g/l) na dose de 96 g i.a./ha apresentaram produção similar à verificada para a testemunha capinada. Não foram observadas diferenças estatísticas entre as produções do clethodim (120 g/l) nas doses de 84 e 96 g i.a./ha e clethodim ( $240 \mathrm{~g} / \mathrm{l})$. Ressalta-se que, o transplantio da cebola foi realizado em época um pouco tardia para a região, fato que provocou a baixa produtividade do experimento. $\mathrm{O}$ número elevado de plantas daninhas presentes no experimento, resultou em condições difíceis de controle, acentuando as diferenças no controle e na produção verificadas entre a menor dose de clethodim (120 g/l) e o clethodim na formulação de $240 \mathrm{~g} / \mathrm{l}$. Para o transplante realizado em setem- bro, a cultura deve permanecer sem a interferência das plantas daninhas nos primeiros 42 dias (Guimarães \& Torres, 1989) e, para o clethodim (240 g/l) e clethodim $(120 \mathrm{~g} / \mathrm{l})$ nas doses de $84 \mathrm{e}$ 96 g i.a./ha, observou-se um controle eficiente até esse período, mostrando serem tratamentos adequados para evitar perdas na produtividade.

\section{LITERATURA CITADA}

ANDREI, E. Compêndio de Defensivos Agrícolas. São Paulo: Organização Andrei Editora Ltda., 1993. 448 p.

FERREIRA, J.C. Avaliação de herbicidas aplicados em pré e pós-emergência na cultura da cebola (Allium cepa L). Planta Daninha, v.9, n.1/2, p. 97-105, 1985.

GUIMARÃES, D.R.; TORRES, L. Plantas daninhas na cultura da cebola. Agropecuária Catarinense, v. 2, n. 1, p. 16-9, 1989.

LORENZI, H. Manual de Identificação e Controle de Plantas Daninhas. $4^{\mathrm{a}}$ ed. Nova Odessa - SP. Editora Plantarum, 1994.

MASCARENHAS, M.H.T. Incidência e controle de plantas daninhas em área irrigadas. Prudente de Morais, MG, EPAMIG-CRCO. 1986. 11p. (mimeog).

MASCARENHAS, M.H.T; ROCHA, F.E.C. Panorama da mecanização na olericultura brasileira. Informe Agropecuário, Belo Horizonte, v.6, n. 169 , p. 5-10, 1991.
PALLER, E.C.Jr.; GUANTES, M.M.; SORIANO, J.M.; VEGA, M.R. Duration of weed competition and control and yield. II.Transplanted onions. The Philippine Agriculture, v. 55, n. 516, p. 221-224, 1971.

PITELLI, R.A.; DURIGAN, J.C. Terminologia para períodos de controle e de convivência das plantas daninhas em culturas anuais e bianuais. In: CONGRESSO BRASILEIRO DE HERBICIDAS E PLANTAS DANINHAS, 15, 1984, Belo Horizonte. Resumos... Belo Horizonte: SBHED, 1984. p. 37.

RODRIGUES, B.N. Guia de Herbicidas. Benedito Noedi Rodrigues e Fernando Sousa de Almeida. 4. ed. Londrina - PR. 1998. 648 p.

SCHADBOLT, C.A.; HOLM, L.G. Some quantitative aspects of weed competition in vegetable crops. Weed, v. 4, n. 2, p. 111-123, 1956.

SOCIEDADE BRASILEIRA DA CIÊNCIA DAS PLANTAS DANINHAS. Procedimentos para instalação, avaliação e análise de experimentos com herbicidas. Londrina: SBCPD, 1995. $42 \mathrm{p}$.

VELINI, E. Estudo e desenvolvimento de métodos experimentais e amostrais adaptados à matologia. Jaboticabal, FCA/UNESP. 1995. 250 p. (Tese doutorado) 